\title{
APLICAÇÃO DE SIG NA ANÁLISE DA REDUÇÃO DA PAISAGEM VERDE NA AVENIDA SÃO RAFAEL EM SALVADOR-BA
}

\author{
THE USE OF GIS IN THE ANALYSIS OF GREEN SPACES SHORTENING ON SÃO RAFAEL \\ AVENUE - SLAVADOR - BAHIA
}

\author{
MASCARENHAS, Adriano Nascimento \\ Geógrafo e estudante de mestrado do Programa de Pós-Graduação em Engenharia Ambiental Urbana \\ da UFBA. \\ E-mail: geoadri@terra.com.br
}

CUNHA, Rita Dione Araújo Cunha

Professora doutora adjunta da Faculdade de Arquitetura da UFBA.

E-mail: ritadi@uol.com.br

\section{RESUMO}

Ortigo trata de uma experiência prática utilizando a ferramenta SIG (Sistema de Informações Geográficas) para analisar o processo de transformação da paisagem nas áreas próximas à avenida São Rafael em Salvador-BA, dando ênfase à observação da diminuição de áreas verdes, ao longo de décadas. $O$ artigo visa demonstrar como a tecnologia do geoprocessamento e a utilização de software específico podem ajudar em estudos sobre a paisagem urbana, auxiliando o entendimento dos processos de ocupação do solo e da qualificação ambiental das cidades.

Palavras-chave: SIG, paisagem verde, uso e ocupação do solo.

\begin{abstract}
This work presents an experience using GIS (Geographic Information Systems) as a tool to analyse landscape changes in an important avenue named "avenida São Rafael" in Salvador-BA, observing reduction of green areas for decades. The work aims to show how data processing and specific software can help urban landscape studies to understand the use and occupation of land to obtain city environmental qualify.
\end{abstract}

Key words: GIS, green landscape, using and occupation urban land process.

\section{1 - Introdução}

Na cidade de Salvador é notório o crescente processo de diminuição de áreas verdes, a partir da década de 1950, quando a cidade iniciou um processo de urbanização e crescimento através de aberturas de avenidas de vale e adensamento de áreas mais distantes do centro. Em particular, a área denominada de "Miolo" engloba uma das áreas de expansão da cidade, onde mais intensamente e mais rápido tem ocorrido transformações em decorrência do processo de ocupação do solo (FERNANDES, 2004). Neste trabalho, percebe-se o acelerado crescimento da mancha urbana sobre o "Miolo" que poderia ser amenizado com um melhor aproveitamento das áreas verdes remanescentes. A avenida São Rafael como um dos eixos vetores da área do Miolo propiciou o processo de transformação da paisagem a sua volta e, com a sua abertura e implantação, teve início o processo de redução das áreas verdes naturais.

Para analisar os fenômenos espaciais urbanos em diferentes escalas, a evolução da cartografia e das ferramentas do geoprocessamento torna-se quase que imprescindível. Segundo Cirilo \& Mendes (2001, p. 15), "o geoprocessamento se insere como uma ferramenta que tem a capa214 cidade de manipular as funções que representam os processos ambientais, em diversas regiões de uma forma simples e eficiente, permitindo uma economia de recursos e tempo". Isso permite agregar dados de diferentes fontes sejam imagens de satélite, mapas cadastrais, GPS, laser, radar, mapas topográficos, mapas de solos, dentre outros e diferentes escalas. O SIG, de acordo 
com os mesmos autores, "é um sistema para capturar armazenar, integrar, manipular, analisar, e apresentar dados que são refenciados na Terra" (Op. cit., 2001).

Este artigo trata de uma experiência usando a ferramenta SIG (Sistema de Informações Geográficas) para analisar o processo de diminuição de áreas verdes e o conseqüente surgimento do ambiente construído nas adjacências da avenida São Rafael em Salvador-BA. Esse estudo permitiu mostrar como o SIG auxilia a detecção das transformações da paisagem nos processos de expansão urbana, ao longo de várias décadas, fornecendo dados de natureza qualitativa e quantitativa para a análise da paisagem urbana. Enfatiza-se que este artigo é resultado de parte de um trabalho de pesquisa de mestrado do Programa de Pós-Graduação em Engenharia Ambiental Urbana da Universidade Federal da Bahia.

\section{2 - Delimitação da área de estudo}

Qualquer pesquisador que necessite trabalhar com a realidade dos bairros da cidade de Salvador enfrentará um sério problema, que é delimitá-los. Pois, em qualquer órgão oficial ou não oficial da cidade não existe uma delimitação geográfica dos mesmos. Diante desta realidade, cabe ao pesquisador trabalhar com Setores Censitários, Zl's (Zonas de Informação) ou RA's (Regiões Administrativas) ou finalmente, utilizar o esforço e o bom censo, explicando o porque de se trabalhar utilizando o determinado procedimento de delimitação.

A avenida São Rafael está inserida no Miolo da cidade. O Miolo de Salvador é assim denominado desde os estudos do Plano Diretor de Desenvolvimento Urbano para a Cidade de Salvador (FERNANDES, 1992), da década de 1970. A região é denominada miolo por se situar geograficamente na parte central do município de Salvador. Possuindo cerca de 115 km², está entre a BR-324 e a avenida Paralela, estendendo-se desde o bairro de Pernambués (Invasão Saramandaia) até o limite norte do município.

A área do Miolo é muito extensa e sofreu um incremento na ocupação do solo muito grande em relação a outras áreas da cidade. O Miolo abrange vários eixos vetores da cidade representados por avenidas importantes, sendo a avenida São Rafael uma das mais relevantes por atravessar áreas relativamente novas na cidade. Pode-se dizer que a avenida foi responsável pela intensa transformação da paisagem local, ao longo de quatro décadas, e, por esse motivo, foi eleita como a área de estudo da pesquisa que resultou neste artigo. A área de estudo apresenta, desde a origem da avenida São Rafael, um crescente processo de uso e ocupação do solo dividido em ocupação habitacional, institucional e comercial. Apesar disso, ainda possui um alto índice de áreas verdes, comparando com a realidade atual da cidade de Salvador e, por isso mesmo, merece que se façam estudos para subsidiar o planejamento dessas áreas verdes remanescentes, preservando a paisagem natural tão necessária à qualidade ambiental satisfatória.

A delimitação da área de estudo abrange toda a avenida São Rafael e adjacências, estendendo-se por um trecho que vai além da avenida Gal Costa, encontrando uma parte do bairro de Sussuarana, totalizando uma área de 2,78 $\mathrm{km}^{2}$. A Figura 1 mostra o polígono que delimita a área de estudo mostrando a avenida cortando centralmente a área.

\section{3 - A utilização do SIG e a análise da área de estudo, de 1959 a 2002}

A metodologia deste trabalho consistiu em utilizar a tecnologia de geoprocessamento (Sistema de Informações Geográficas - SIG) através de fotografias aéreas das cinco últimas décadas para quantificar a diminuição das áreas verdes e o crescimento do ambiente construído.

Para visualizar espacialmente e quantificar as informações, foram utilizadas fotografias aéreas de 1959 (tomadas pela empresa Petrobrás), além de fotografias de 1976, 1980, 1989, 1992, 1998 e 2002 (executadas para a Companhia de Desenvolvimento Urbano do Estado da Bahia 
- CONDER). Para o georreferenciamento das fotografias (técnica de atribuir coordenadas reais às imagens), utilizou-se o software ARCGIS MAP $8.3^{\circledR}$, tomando como referência a base cartográfica do Sistema Cartográfico da Região Metropolitana de Salvador - SICAR (1992) e para a composição (vetorização) dos temas (shapes) foi utilizado o software ArcView 3.2a ${ }^{\circledR}$. Depois das magens georreferenciadas, foram quantificadas as áreas verdes representadas na Figura 1.

Classificando as legendas de cada tema, consegue-se as respostas que podem ser observadas nos layouts das Figuras 2 a 8 e suas respectivas análises da evolução do crescimento urbano.

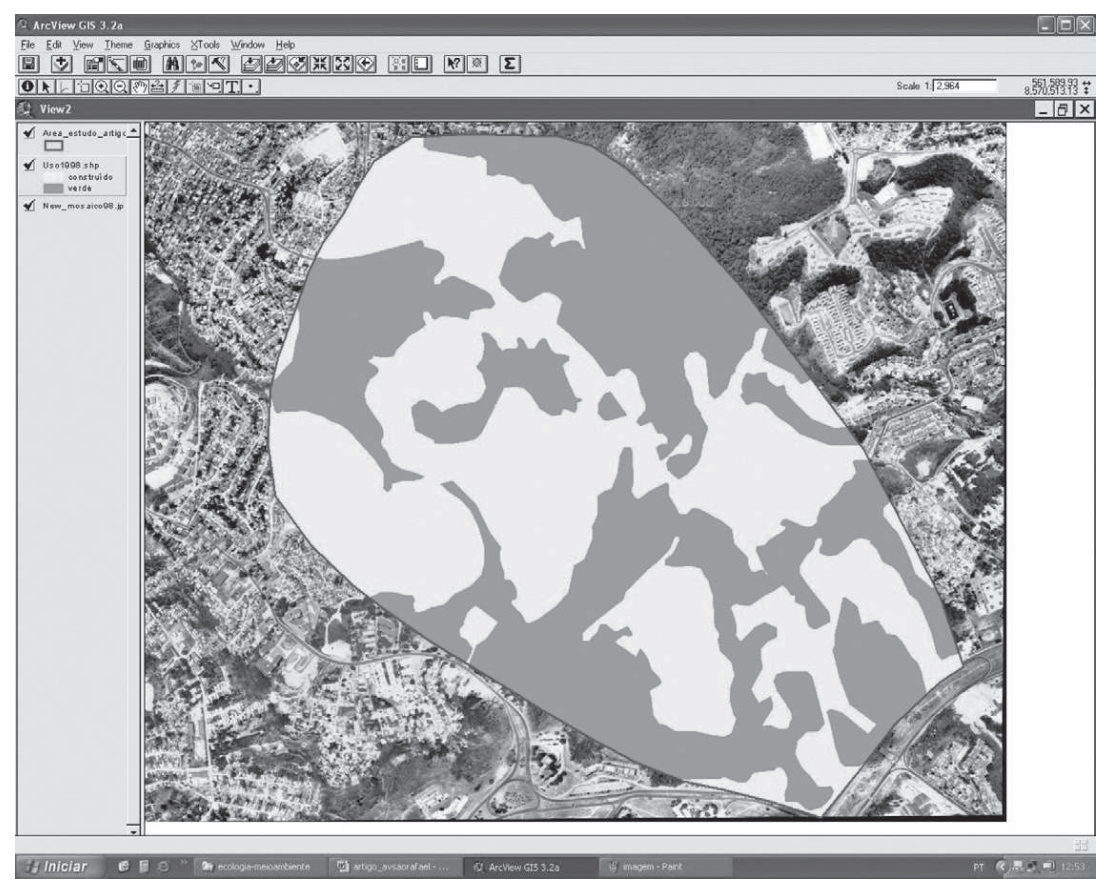

Figura 1: Visualização das áreas verdes remanescentes na área de estudo em 2002

Fonte: CONDER, vôo de 2002

De acordo com os dados da Figura 2, pode-se observar que, no ano de 1959, ainda não existia a construção de edificações relevantes nem estradas pavimentadas. A localidade era caracterizada por uma vegetação densa (primária) e por pequenas vias não pavimentadas e algumas edificações de pequeno porte. A avenida São Rafael ainda não estava implantada, embora o processo de antropoformização da paisagem já esteja evidente.

Analisando a Figura 3, percebe-se que, no ano de 1976, a vegetação densa ainda predominava e a avenida São Rafael já estava construída. A área do polígono de número 1 identificado na foto mostra o trabalho de terraplanagem para a futura construção do Conjunto Habitacional Recanto das llhas e os polígonos 2 e 3 determinam o desmatamento e terraplanagem para futuras construções não identificáveis.

Até meados de 1970 do século XX, a paisagem verde ainda era predominante e o processo de ocupação do solo ainda se fazia em ritmo lento. Este recebe um impulso na década seguinte, como mostra a Figura 4.

$\mathrm{Na}$ Figura 4 percebe-se a iniciativa de construções mais relevantes. Na área do polígono de número 4, inicia-se a terraplanagem para a construção de um departamento da Companhia Hidrelétrica do Rio São Francisco - CHESF. No polígono 5 detecta-se a terraplanagem para a construção do Conjunto Habitacional Colinas de Pituaçu. Na área do polígono 6, identifica-se a construção da rótula que faz a interligação entre a avenida São Rafael, a avenida São Marcos 216 e a Via Regional (atual bairro Nossa Senhora da Vitória). E na área 7, vê-se a construção do Hotel Le Royale.

Percebe-se na Figura 5, que a construção dos conjuntos habitacionais já citados foram concluídas. No polígono 2 surgem novos conjuntos habitacionais denominados Vivendas dos Pássaros, 

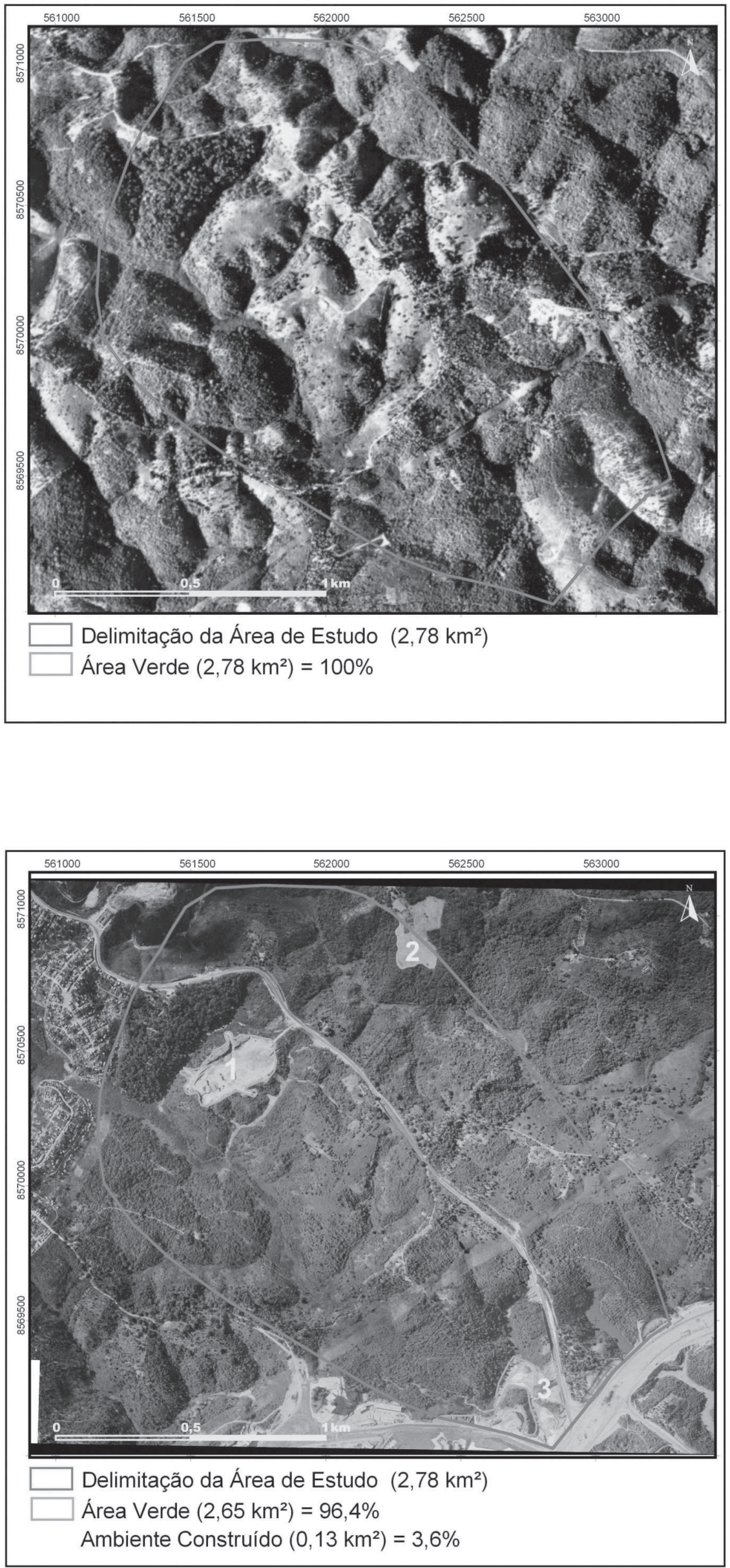

Figura 2: A área de estudo em 1959

Fonte: Petrobrás, vôo de 1959

Figura 3: A área de estudo em 1976

Fonte: CONDER, vôo de 1976 

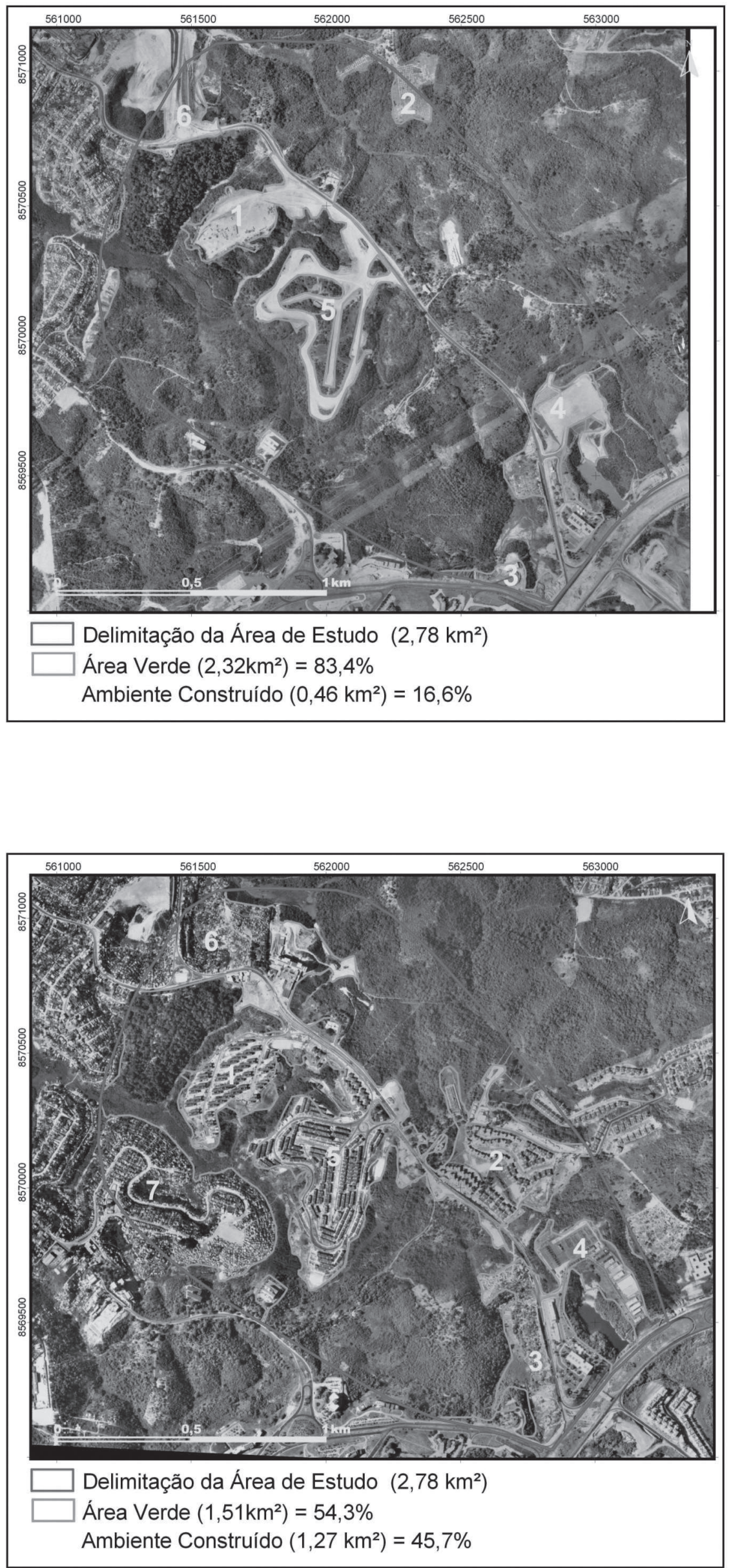

Figura 4: A área de estudo em 1980 Fonte: CONDER, vôo de 1980

Figura 5: A área de estudo em 1989 Fonte: CONDER, vôo de 1992 
Moradas do Campo e uma parte do Conjunto Vale dos Lagos. No polígono 6 é construído o Hospital São Rafael. Também nos polígonos 6 e 7, percebe-se um crescente processo de ocupação espontânea. Embora dominante, o verde começa a sofrer reduções mais drásticas com a construção de extensas áreas residenciais e de equipamentos urbanos.

Analisando a Figura 6, percebe-se que no polígono 8 é construído um condomínio de maior porte que os demais denominado Bosque Imperial. Isso determina que o crescimento vertical de maior porte é resultante de maior valorização da terra.
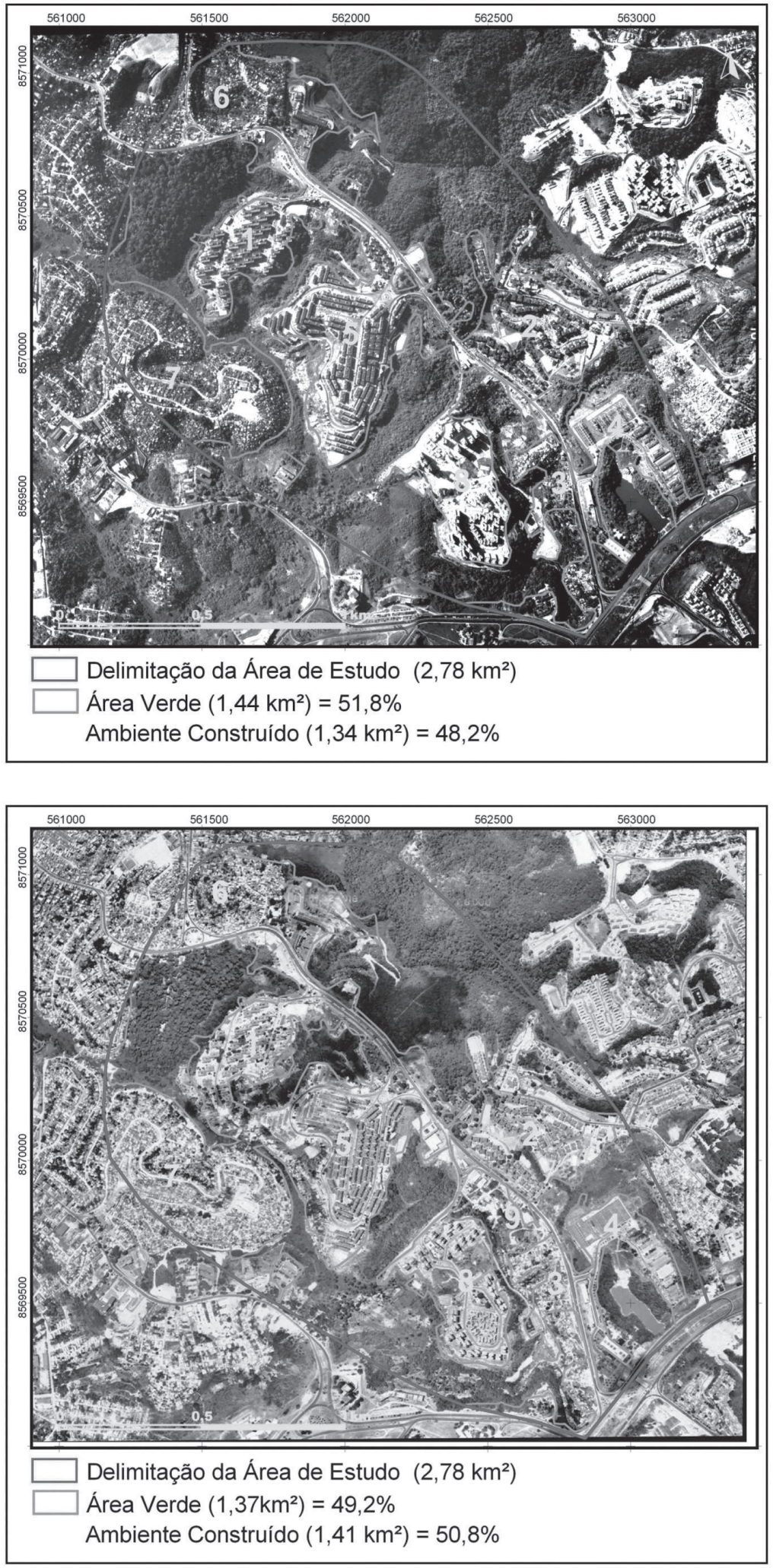

Figura 6: A área de estudo em 1992 Fonte: CONDER, vôo de 1992

Figura 7: A área de estudo em 1998 Fonte: CONDER, vôo de 1992 


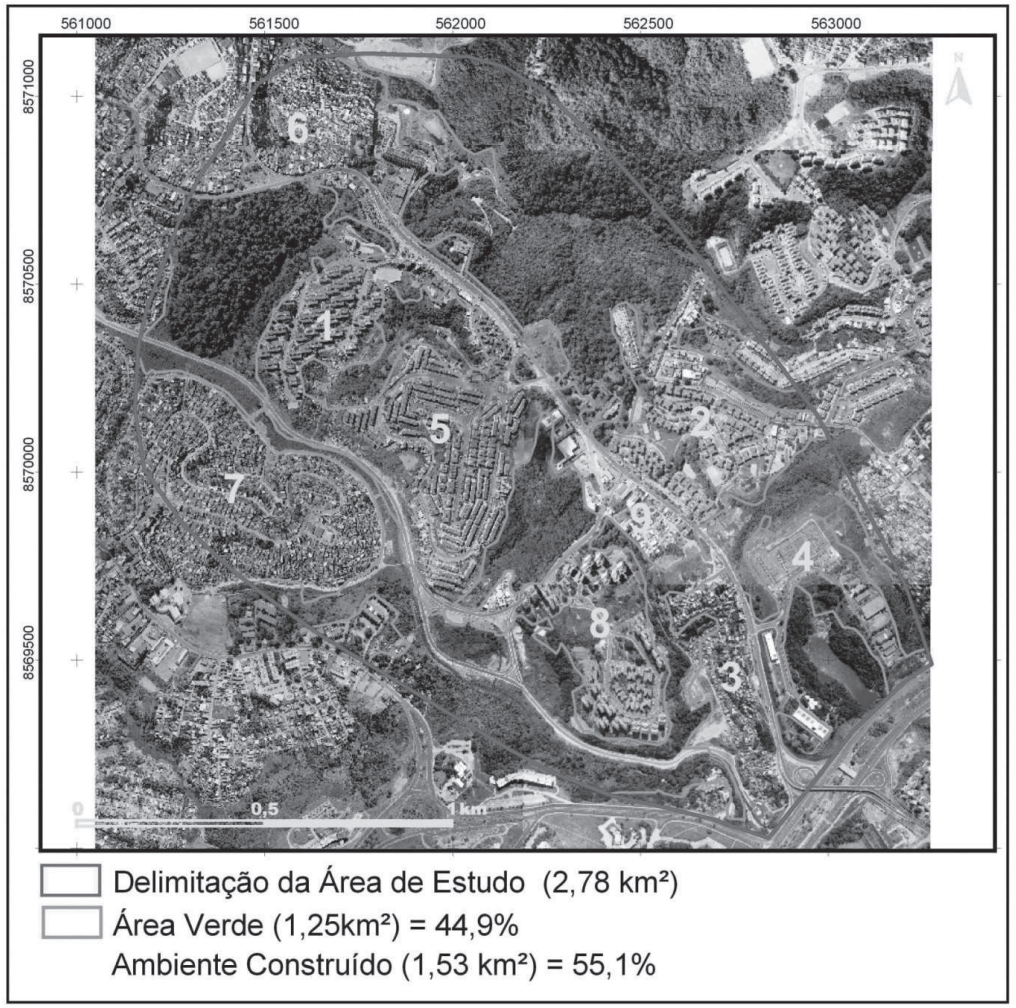

Figura 8: A área de estudo em 2002 Fonte: CONDER, vôo de 2002

Comparando as Figuras 6 e 7, percebe-se um aumento do ambiente construído caracterizado por ocupação espontânea, principalmente nas partes de encostas. E no polígono 9 da Figura 7 são construídos dois shopping centers (Ponto Alto I e II), um supermercado e um posto de gasolina. São equipamentos que dispõe de serviços (correios, farmácias, dentre outros) fundamentais para a demanda local.

A Figura 8 representa a fotografia mais atual do acervo. Percebe-se que entre as áreas dos polígonos 1 e 7 foi construída a avenida Gal Costa, uma avenida de vale que faz a ligação entre a avenida Luís Eduardo Magalhães (ou avenida Paralela) e a BR-324. Ressalta-se também que, as localidades de ocupação espontânea são presentes tanto em setores que já começaram sem planejamento quanto em áreas que tinham o objetivo ser planejadas e melhor estruturadas, como exemplo das encostas dos conjuntos habitacionais.

\section{Resultados e conclusões}

De acordo com a realidade local da área de estudo deste artigo, é notório o processo de diminuição de áreas verdes (observado na Tabela 1). Praticamente a metade da área de estudo foi destituída do verde original para dar lugar à paisagem edificada. Isso demonstra de certa forma como os investimentos imobiliários e a demanda por equipamentos urbanos têm sido mais privilegiados e como as áreas verdes têm sido preteridas de uma forma desoladora sem se prestar atenção no seu valor ambiental e paisagístico.

Apesar disso, a área ainda possui um alto índice de áreas verdes naturais, comparando-se com a realidade atual da cidade de Salvador em sua totalidade. Devem ser considerados mais estudos em caráter urgente sobre as áreas verdes remanescentes para planejar melhor o que deve ser suprimido para construções e o que deve ser mantido e preservado, dando ênfase ao potencial paisagístico do local que reserva uma topografia singular e merece um cuidado maior nos projetos de urbanização no sentido de destacar as áreas verdes como elementos de qualificação do ambiente urbano. 


\begin{tabular}{|c|c|c|c|}
\hline ANO & TIPO & Área $\left(\mathrm{km}^{2}\right)$ & Porcentual \\
\hline \multirow{2}{*}{1959} & Área Verde & 2,78 & $100 \%$ \\
\cline { 2 - 4 } & Ambiente Construído & 0 & $0 \%$ \\
\hline \multirow{2}{*}{1976} & Área Verde & 2,65 & $96,40 \%$ \\
\cline { 2 - 4 } & Ambiente Construído & 0,13 & $3,60 \%$ \\
\hline \multirow{2}{*}{1980} & Área Verde & 2,32 & $83,40 \%$ \\
\cline { 2 - 4 } & Ambiente Construído & 0,46 & $16,60 \%$ \\
\hline \multirow{2}{*}{1989} & Área Verde & 1,51 & $54,30 \%$ \\
\hline \multirow{2}{*}{1992} & Ambiente Construído & 1,27 & $45,70 \%$ \\
\cline { 2 - 4 } & Área Verde & 1,44 & $51,80 \%$ \\
\hline \multirow{2}{*}{1998} & Ambiente Construído & 1,34 & $48,20 \%$ \\
\cline { 2 - 4 } & Área Verde & 1,37 & $49,20 \%$ \\
\hline \multirow{2}{*}{2002} & Ambiente Construído & 1,41 & $50,80 \%$ \\
\cline { 2 - 4 } & Área Verde & 1,25 & $44,90 \%$ \\
\cline { 2 - 4 } & Ambiente Construído & 1,53 & $55,10 \%$ \\
\hline
\end{tabular}

Tabela 1: Evolução do processo de redução das áreas verdes na área de estudo

Atualmente, para analisar espacialmente as questões urbanas as ferramentas de geoprocessamento são fundamentais. O SIG tem se mostrado uma ferramenta útil, pois além de obter dados importantes sobre a paisagem urbana, os resultados conseguidos são passíveis de atualizações permanentes. No caso deste trabalho a utilização do SIG atendeu satisfatoriamente ao objetivo estabelecido de analisar o processo de uso e ocupação do solo e sua influência sobre a diminuição das áreas verdes nas proximidades da avenida São Rafael.

Constata-se pela análise temporal das fotos que o sítio já possuía uma tendência de urbanização, mesmo antes da implantação da avenida São Rafael. Porém as mais drásticas mudanças na paisagem foram provocadas, após a construção da avenida, pois esta possibilitou o acesso à área, ligando-a a outras áreas importantes de Salvador.

Como a tendência de crescimento da cidade continua invadindo o Miolo, até porque este ainda apresenta extensas áreas não ocupadas, a área de estudo que abrange a avenida São Rafael torna-se um importante elemento do Miolo para estudos de planificação urbana e de monitoramento das áreas verdes, sob pena do desenfreado processo de ocupação vir a dizimar, em pouco tempo, o que resta de paisagem verde.

\section{Bibliografia}

CIRILO, José A.; MENDES. Geoprocessamento em recursos hídricos - Princípios, integração e aplicação. Associação Brasileira de Recursos Hídricos - ABRH, 2001.

FERNANDES, R. B. Periferização sócio-espacial em Salvador: Análise do Cabula, uma área representativa. Salvador, 1992.

FERNANDES, Rosali B. Processos recentes de urbanização em Salvador: O Miolo, região popular e estratégica da cidade. Biblio 3W, Revista Bibliográfica de Geografia y Ciencias Sociales, Barcelona: Universidad de Barcelona, v. IX, 523, 20 de julio de 2004.

FERRARI, Célson. Curso de planejamento municipal integrado - Urbanismo. 6. ed. São Paulo: Pioneira, 1997.

SALVADOR. Companhia de Desenvolvimento da Região Metropolitana de Salvador - Plano de ocupação para a área do miolo de Salvador. Salvador: Secretaria de Planejamento Municipal, 1985.

SOUZA, Ângela Gordilho: Habitar contemporâneo: Novas questões no Brasil nos anos 90. Salvador: FAUUFBA, 1997. 